\title{
Ankle sprain: pathophysiology, predisposing factors, and management strategies
}

This article was published in the following Dove Press journal:

Open Access Journal of Sports Medicine

12 July 2010

Number of times this article has been viewed

\author{
Tricia J Hubbard \\ Erik A Wikstrom \\ UNC Charlotte, Department \\ of Kinesiology, Charlotte
}

Correspondence: Tricia J Hubbard UNC Charlotte, Department of Kinesiology, 920I University City Blvd, Charlotte, NC 28223, USA

Tel +l 7046876202

Fax + I 7046873350

Email thubbarl@uncc.edu

\begin{abstract}
With the high percentage (up to 75\%) of initial lateral ankle sprains (LAS) leading to repetitive sprains and chronic symptoms, it is imperative to better understand how best to treat and rehabilitate LAS events. The purpose of this paper is to review LAS pathophysiology, predisposing factors, and the current evidence regarding therapeutic modalities and exercises used in the treatment of LAS. Functional rehabilitation, early mobilization with support, is the current standard of care for LAS. However, the high percentage of reinjury occurrence and development of chronic symptoms (up to 75\%) after a LAS, suggests the current standard of care may not be effective. Recent evidence has shown the need for more stringent immobilization to facilitate ligament healing and restoration of joint stability and function after a LAS. Additionally, the importance of adding adjunctive therapies, specifically joint mobilizations and balance training have been shown to improve function and decrease the incidence of reinjury after a LAS. Modifying current rehabilitation protocols to include protecting the ankle joint with stringent immobilization, and including joint mobilizations and balance training may be the first step to decreasing the incidence of short and long term ankle joint dysfunction.
\end{abstract}

Keywords: rehabilitation, recurrent sprains, chronic ankle instability (CAI)

\section{Introduction}

Lateral ankle sprains (LAS) are among the most common injuries suffered during athletic/recreational activities and the sequela often plague patients for the remainder of their lives. ${ }^{1,2}$ Specifically, more than 23,000 ankle sprains are estimated to occur per day in the United States which equates to approximately one sprain per 10,000 people daily. ${ }^{3}$ Despite the frequency of LAS, the injury is often erroneously considered to be an inconsequential injury. As a result of the societal insignificance assigned to LAS, about $55 \%$ of individuals who sprain their ankle do not seek treatment from a health care professional, ${ }^{4}$ thus, the true incidence of injury may be much greater. Even more concerning is the high proportion (as much as $70 \%$ ) of patients that will suffer from repetitive LAS, and chronic symptoms after the initial injury. ${ }^{4}$ The development of these residual symptoms has been termed chronic ankle instability (CAI). Not only does CAI limit physical activity, ${ }^{5}$ but $\mathrm{CAI}$ also leads to articular degeneration of the talus, and an increased risk of osteoarthritis (OA). ${ }^{6,7}$

With the high incidence of CAI and potential for the development of ankle OA, it is essential that LAS are managed effectively from the onset. Therefore, the purpose of this paper is to review three areas that are important if we are to properly treat LAS and prevent the development of CAI: 1) LAS pathophysiology, 2) predisposing factors 
of LAS, and 3) the current evidence regarding therapeutic modalities and exercises used in the treatment of LAS.

\section{Pathophysiology}

LAS result in damage to the passive ligamentous structures of the ankle. Indeed, forceful ankle plantar flexion and inversion, the most common mechanism of injury, often leads to tearing of the lateral ligaments of the ankle. Specifically, the anterior talofibular ligament (ATFL), reported to be the weakest is first ligament injured. ${ }^{8}$ Rupture to the ATFL is followed by damage to the calcaneofibular ligament (CFL) and finally to the posterior talofibular ligament (PTFL). ${ }^{8}$ Isolated injury to the ATFL occurs in $66 \%$ of LAS while ATFL and CFL ruptures occur concurrently in another $20 \% .{ }^{8}$ The PTFL is not commonly injured because of the large amount of force required to cause damage, as well as the amount of dorsiflexion needed to strain the ligament. The amount of dorsiflexion necessary to strain the PTFL places the ankle in a closed packed and thus more stable position which decreases the likelihood of injury to the ligament. In addition to the lateral ligamentous structures of the talocrural joint, the subtalar ligaments can also be injured. Rubin and Witten ${ }^{9}$ were the first to examine subtalar instability as an independent clinical entity; however, they assumed that injury to the subtalar joint often occurs in combination with injury to the lateral ankle ligaments. Further the incidence of subtalar instability is estimated to be between $75 \%$ to $80 \%$ in individuals with CAI. ${ }^{10,11}$

With damage to the ligamentous stabilizers of the ankle after a LAS, an associated increase in the motion available between the bones of the ankle/foot complex occurs (hypermobility). The resulting hypermobility can be assessed qualitatively and empirically using various clinical techniques such as manual stress tests, instrumented arthrometry and stress radiographs. ${ }^{12-16}$ In order to regain stability of the ankle joint, immediate care and rehabilitation should focus on enhancing ligament healing. Acutely, this occurs by protecting the joint (immobilization, crutch use) then slowly adding exercises that help the newly laid down collagen align with the forces of the ankle. ${ }^{17}$ The current literature suggests it takes over six weeks for ligament healing to occur. ${ }^{18-24}$ However, studies have also documented joint laxity six months after injury. ${ }^{20,23}$ The chronic laxity that has been reported in the literature may be due to inappropriate rehabilitation, which necessitates the need for further investigation into the type of care and treatment that will best facilitate tissue healing, and normal joint function.

\section{Predisposing factors}

Research to identify predisposing risk factors is vital to preventing LAS. Indeed, this type of research attempts to identify specific characteristics (both intrinsic and extrinsic) that increase an individual's chance of suffering a LAS. However, the greatest benefit of risk factor research is that the findings allow clinicians to apply focused therapeutic interventions to correct and/or limit the effects of identified risk factors. However, there are few prospective studies that have examined predisposing factors to LAS, but the research that has been conducted has reported several intrinsic and extrinsic risk factors. Numerous intrinsic factors have been examined, but the most correlated factor is a history of a previous ankle sprain. ${ }^{25}$ Unfortunately, the literature remains unclear, with several studies reporting that a history of a previous LAS both increases ${ }^{4,26,27}$ and has no effect ${ }^{28,29}$ on an individual's risk of suffering a recurrent LAS. Additional factors that have been reported to increase an individual's risk of recurrent LAS include: height and weight, ${ }^{29}$ limb dominance, ${ }^{26}$ ankle joint laxity, ${ }^{28}$ anatomical alignment, ${ }^{30}$ muscle strength ${ }^{28}$ muscle reaction time ${ }^{25}$ and postural sway. ${ }^{31}$ Further prospective research is necessary to better understand if these factors actually predispose patients to LAS.

Similar to intrinsic risk factors, the literature has consistently reported that patients with a previous history of LAS who wear ankle braces or tape have a lower incidence of LAS than those that do not. ${ }^{4,13,29}$ Research hypothesizes the reduction in LAS may be due to either the mechanical support or the enhanced proprioception offered by the brace or both. Based on the available evidence, it appears that having patients, especially those with a previous LAS wear ankle braces and/or athletic tape when participating in physical activity is an effective means of preventing recurrent LAS. Additionally, a cost-benefit analysis conducted by Olmsted et $\mathrm{al}^{32}$ indicated that braces are better in terms of cost savings compared to tape. Other extrinsic factors that have been examined include shoe type and duration/intensity of competition and player position. ${ }^{25}$ The research has not shown either factor to significantly increase or decrease the risk of developing or reinjuring the ankle. Further prospective research is needed to further evaluate both intrinsic and extrinsic factors of LAS. The evidence overall supports the use of ankle bracing as an effective means to reduce the risk of LAS. 25

\section{Management strategies}

Acute LAS management typically involves rest, ice, compression, elevation (RICE) and functional rehabilitation 
(ie, early mobilization with support). ${ }^{17}$ In more severe cases, LAS are treated with crutches and are typically immobilized for a few days. ${ }^{17}$ To date, numerous investigations have assessed the efficacy of rehabilitation techniques in improving clinical outcomes after LAS. ${ }^{33,34}$ The research that has been done has primarily focused on short-term outcomes including: pain, range of motion (ROM), and return to work/ activity. However, the high percentage of reinjury occurrence (up to $70 \%)^{4}$ and development of CAI (up to $75 \%$ ) after an LAS, suggests that further research of both short and long-term outcomes following rehabilitation is needed. Currently, cross-sectional and case-control investigations have identified numerous mechanical and neuromuscular impairments in subjects with CAI and post-traumatic ankle OA, the long-term sequela of acute LAS. More importantly, research has indicated that many of these impairments can be treated with a variety of therapeutic modalities and exercises. The three impairments that have been implicated as causes of CAI, and are the focus of this paper, include increased joint laxity, arthrokinematic impairments, and balance deficits.

\section{Acute care/immobilization}

Immediately after a LAS the primary goals are to manage pain, control inflammation and protect the joint so that the healing process can begin. In the acute phase of healing, the most important structures to protect are the lateral ligaments of the ankle because the traumatic mechanism has caused increased laxity. In the past, the majority of the literature has focused on functional rehabilitation after a LAS. But with the high recurrence rates of LAS, development of CAI and potential for the development of ankle OA, functional rehabilitation may not allow adequate time for the ligaments of the ankle to heal and stability to be restored. Indeed, increased laxity has been reported using both subjective (ankle giving way, or feelings of instability) and objective (manual stress tests, radiographs) outcome measures. ${ }^{18-24,35}$ Unfortunately, ankle laxity often persists despite treatment. Specifically, positive anterior drawer tests were still present in 3\%-31\% of subjects six months after injury ${ }^{20}$ and feelings of instability were present in $7 \%-42 \%$ of subjects up to one year after injury. $19,21,22,24$

There remains a large need for data obtained from reliable and quantifiable methods of measuring ankle laxity. For example, Hubbard and Cordova ${ }^{35}$ assessed the natural recovery of ankle ligament laxity after an acute LAS with an instrumented ankle arthrometer. More specifically, the authors quantified the anterior-posterior load displacement and inversion-eversion rotational laxity characteristics of the ankle-subtalar joint complex within three days after injury and again eight weeks after injury. The results indicate that ankle laxity did not significantly decrease over eight weeks which suggests that the lateral ligaments of the ankle need to be protected for longer than eight weeks if mechanical stability is to be restored after an acute LAS ${ }^{35}$ Cumulatively, these studies provide strong evidence that better and longer protection of the ankle joint after an acute LAS is needed to help restore mechanical stability. ${ }^{35}$ If mechanical stability is not restored, increased laxity could lead to further mechanical adaptations (ie, greater laxity, altered joint alignment), deficits in sensorimotor control (ie, impaired balance, altered movement patterns) and recurrent injury as a maladaptive compensation of the changes in joint laxity and/or sensorimotor control.

To help examine the effects of immobilization, a multicenter prospective randomized control trial was conducted examining three different mechanical supports (Aircast brace, Bledsoe boot or 10-day below the knee cast) compared with that of a double-layer tubular compression bandage (current standard of care) in promoting recovery after severe LAS. ${ }^{36}$ A total of 584 patients with LAS were followed over nine months. The primary outcome was the quality of ankle function measured using the Foot and Ankle Score. They reported patients that received a below-knee cast had a more rapid recovery than those given the tubular compression bandage with clinically important benefits in quality of ankle function at three months post injury. ${ }^{36}$ Bledsoe boots were reported to be the least effective treatment throughout the recovery period. Based on the data, a short period of immobilization in a below-knee cast or Aircast ankle brace may result in faster recovery than the current standard of care. Additionally, the authors recommended the below-knee cast because it showed the widest range of benefit. However, future research is needed to determine if similar benefits will be found in more objective measures such as ligament laxity and postural control.

An earlier study by Beynnon et al ${ }^{37}$ also examined the type of immobilization that had the best outcomes. The authors stratified acute LAS based on the grade (I, II, or III). Patients were then randomized to undergo functional treatment with different types of ankle immobilization. They compared an elastic wrap (current standard of care), Air-Stirrup ankle brace, Air-Stirrup ankle brace with an elastic wrap and fiberglass walking cast. They reported treatment of grade I and grade II ankle sprains with Air-Stirrup brace combined with elastic wrap allowed patients to return to preinjury function quicker than the other immobilizers. ${ }^{37}$ For grade III sprains, 
there were no differences between the Air-Stirrup brace and the fiberglass walking cast. The subjects in the Lamb et $\mathrm{al}^{36}$ study were considered to have severe ankle sprains, which may be why they reported the below-knee cast as most favorable. In less severe sprains (grade I and grade II) less stringent immobilization like an Air-Stirrup brace combined with elastic wrap may best restore function, but in more severe cases the below-knee cast may best enable return to normal function.

Based on the research available to best treat acute LAS, some form of immobilization needs to be used to help protect the joint and allow ligament healing to occur. Thus, elastic or tubular wraps are not recommended because research suggests that they do not provide adequate protection to allow restoration of function. An Air-Stirrup brace with elastic wraps for grade I and grade II, and below-knee casts for grade III may be the best treatment strategy to prevent long term pathology. After a period of controlled immobilization functional exercises are necessary to rehabilitate the joint. Research needs to examine which adjunctive therapies are best to rehabilitate and prevent CAI once joint stability has been restored.

\section{Joint mobilizations}

To date manipulative therapy techniques; including Maitland's mobilizations, ${ }^{38,39}$ Mulligan's mobilizations with movement, ${ }^{40-42}$ and high-velocity low-amplitude (HVLA) thrusts, ${ }^{43-46}$ have all been postulated to be effective treatments for acute LAS. Indeed, manipulative therapy techniques are theorized to reduce pain, improve function and increase ROM via the restoration of arthrokinematic motions (ie, roll, glide, spin), ${ }^{47}$ thus recommendations to use these techniques make intuitive sense. Further, there is a great deal of anecdotal evidence in the form of published case studies supporting the use of manipulative therapies to improve various outcome measures in acute LAS. ${ }^{48-50}$

A recent systematic review ${ }^{51}$ indicated that multiple HVLA thrusts delivered over several treatment sessions resulted in a statistical trend towards improving pain pressure scores and self-report levels of pain. ${ }^{52}$ Further, a single treatment session, which involved multiple osteopathic and manipulative techniques, immediately reduced self-reported pain relative to a control group in patients with acute LAS. $^{53}$ Similarly, studies that used multiple manipulative techniques $^{54,55}$ delivered over several treatment sessions reported significant improvements in pain outcome measures. Thus, the current data strongly suggest that multiple manipulative therapy treatments are needed to improve outcome measures associated with pain in patients with acute LAS. However, the exact number of treatments and the dosage within each treatment session remains unknown and should be the focus of future research.

The available literature also indicates that both active and passive ROM have improved following the delivery of multiple treatment sessions consisting of Maitland's mobilization ${ }^{56}$ and HVLA thrusts. ${ }^{52}$ Additionally, significant improvement in non-weight bearing ROM was reported after the delivery of a variety of manipulative therapy techniques over a two week intervention. ${ }^{54}$ However, single treatment sessions regardless of the manipulative therapy technique used have failed to improve ROM in patients with acute $\mathrm{LAS}^{53}$ in patients who had suffered a LAS more than six months prior to testing, ${ }^{57}$ and in uninjured controls. ${ }^{58,59}$ Thus, the cumulative data suggest that multiple treatment sessions are needed to see ROM improvements in patients with acute LAS. However, significant improvements in dorsiflexion ROM have been reported after just a single treatment session of Maitland's (anteroposterior [AP] talocrural) mobilizations ${ }^{60,61}$ in patients who underwent a prolonged period of ankle immobilization for a variety of pathological conditions. ${ }^{62}$ Thus, it appears that even if acute LAS patients are immobilized (ie, casted) following injury, ankle joint mobilizations could be used to help restore ROM.

Functional outcome measures, have also improved following multiple manipulative therapy treatment sessions. ${ }^{52,56}$ Additionally, investigations that used several techniques during multiple treatment sessions also found improvements in self-reported function. ${ }^{54}$ Similarly, a single treatment session consisting of two manipulative therapy techniques lead to an immediate redistribution of foot loading patterns during static stance relative to a placebo laying of hands procedure in patients with acute grade II LAS. ${ }^{63}$ Based on this evidence, it appears that multiple treatment sessions are needed to consistently see improvements in a variety of outcome measures, regardless of the specific manipulative therapy technique used, in patients with acute LAS. However, no investigation has directly compared the effectiveness of different manipulative therapy techniques on any outcome measures in patients with acute LAS. Thus direct comparisons of manipulative therapy techniques should be the focus of future research endeavors.

\section{Balance exercises}

One of the most commonly examined sensorimotor outcome measures following a LAS is single leg postural control. 
A prospective investigation has shown that single leg postural control is impaired for at least four weeks after injury. ${ }^{64}$ Further, recent systematic reviews have demonstrated that postural control is impaired on both the involved limb $b^{65,66}$ and the uninvolved limb ${ }^{66}$ relative to an uninjured control group within six weeks of a LAS. The presence of bilateral balance impairments (ie, impaired balance on the involved and uninvolved limb relative to a healthy reference group $)^{66}$ as well as bilateral alterations at joints proximal to the ankle $\mathrm{e}^{7,68}$ suggest changes in motor control patterns that are centrally mediated (ie, feed-forward neuromuscular control) have occurred. Further, impaired postural control is associated with an increased risk of ankle injury ${ }^{69,70}$ and because of this strong association, balance training is a common component of therapeutic intervention programs used by allied health care practitioners to treat acute LAS. Fortunately, balance training is effective at improving postural control scores in subjects with acute $\mathrm{LAS}^{60}$ and at reducing the risk of recurrent $\mathrm{LAS}^{71-74}$ The effectiveness of balance training is hypothesized to be due to the modality's ability to restore and/ or correct feed-forward and feedback neuromuscular control alterations that have occurred as a result of a LAS. Indeed, neural adaptations occur at multiple sites within the central nervous system as a result of balance training intervention programs. ${ }^{75-78}$ In other words, balance training capitalizes on the incredible plasticity of the central nervous system and enhances a patient's ability to react to both internal and external perturbations. ${ }^{79}$

While balance training improves postural control the exact treatment dosage needed to cause balance improvements and reduce the risk of recurrent injury remains unknown. For example, postural control improvements have been reported after just three days ${ }^{31,79}$ and after weeks ${ }^{31}$ of balance training. While rapid improvements are extremely exciting to patients and clinicians alike, $\mathrm{Bahr}^{80}$ reports that the longer a balance training program is implemented the greater preventative effects accrue from the program. To date, published balance training investigations primarily use prospective cohort designs where the baseline measures represent postural control prior to the intervention but not preinjury postural control values. So while the literature indicates that balance training improves postural control, it is not clear if balance training restores postural control to preinjury balance values.

While balance training is effective in restoring postural control, recent investigations have identified several adjunctive treatments/constructs that may further enhance the effectiveness of balance training including stochastic resonance and the patient's attentional focus. Stochastic resonance (SR) is the introduction of low levels of sub-sensory or mechanical noise into the nervous system during balance training. This technique is believed to enhance the sensorimotor system's ability to detect afferent information from a number of sources which is believed to subsequently result in a more efficient motor response from the central nervous system, a critical component for maintaining balance. ${ }^{81-84}$ SR has improved postural stability in healthy young and elderly individuals when compared to postural stability tests without stimulation present. ${ }^{81-84}$ Additionally, SR stimulation applied during balance training improved both static and dynamic postural stability earlier and with greater efficacy than balance coordination training alone in both healthy and subjects with CAI ${ }^{85,86}$ However, the effectiveness of SR in patients with acute LAS has not been investigated.

Attentional focus, primarily in the field of motor control has also been investigated in an effort to enhance learning motor skills including postural control. There are two types of attentional focus: internal attentional focus (IAF) and external attentional focus (EAF). An example of IAF is when a clinician instructs the patient to 'stand as still as possible' when completing a balance training task and/or program. These instructions direct the patient's attention towards themselves and emphasize an IAF. However, research indicates that an external attentional focus (EAF) (ie, focusing on the effect of their movement) enhances motor skill learning more effectively. ${ }^{87-89}$ For example, an EAF resulted in greater acquisition, retention and transfer of postural control when compared to an IAF in patients with acute LAS..$^{90,91}$ Researchers hypothesize that an EAF facilitates more efficient movement patterns by allowing the sensorimotor system to self-organize, thus allowing the completion of movement patterns to be more automated. ${ }^{88}$

While balance training is effective, the exact dosage, type of exercise and level of intensity needed to improve various indices of postural control and reduce recurrent injury may never been known because these outcomes are most likely multi-factorial in nature. However, balance training is effective and therefore, patients with a history of LAS should complete a balance training program because: 1) balance training is hypothesized to correct feed-forward and feed-back neuromuscular control deficits; ${ }^{75-79}$ 2) balance training improves postural control, a measure associated with an increased risk of sustaining LAS; ${ }^{67,70,73}$ and 3) balance training reduces the recurrence of $\mathrm{LAS}^{71-74}$ 


\section{Conclusion}

Short and long term disability after an acute LAS remains a public health concern. Research reports instability and joint laxity to still be present over six months after injury. Acutely, evidence suggests rigid immobilization as an effective means to help restore joint stability. In addition to the need for proper acute care, two adjunctive therapies should be a part of the rehabilitation process: joint mobilizations and balance training. The literature has reported the benefit of using both to help improve function and balance training has been shown to decrease reinjury rates. Further research is needed to examine dosage of treatments and rehabilitation modalities to best maximize function and prevent chronic joint dysfunction.

\section{Disclosure}

The authors report no conflicts of interest in this work.

\section{References}

1. Fernandez WG, Yard EE, Comstock RD. Epidemiology of lower extremity injuries among US high school athletes. Acad Emerg Med. 2007;14(7):641-645.

2. Hootman JM, Dick R, Agel J. Epidemiology of collegiate injuries for 15 sports: summary and recommendations for injury prevention initiatives. J Athl Train. 2007;42(2):311-319.

3. Kannus P, Renstrom PA. Treatment for acute tears of the lateral ligaments of the ankle. Operation, cast, or early mobilization. $J$ Bone Joint Surg Am. 1991;73:305-312.

4. McKay GD, Goldie PA, Payne WR, Oakes BW. Ankle injuries in basketball: injury rate and risk factors. Br J Sports Med. 2001;35: 103-108.

5. Verhagen RA, de Keizer G, Van Dijk CN. Long-term follow-up of inversion trauma of the ankle. Arch Orthop Trauma Surg. 1995;114: 92-96.

6. Harrington KD. Degenerative arthritis of the ankle secondary to long-standing lateral ligmanet instability. J Bone Joint Surg. 1979;61: 354-361.

7. Hintermann B, Boss A, Schäfer D. Arthroscopic findings in patients with chronic ankle instability. Am J Sports Med. 2002;30(3):402-409.

8. Brostroem L. Sprained ankles. I. Anatomic lesions on recent sprains. Acta Chir Scand. 1964;128:483-495.

9. Rubin $\mathrm{G}$, Witten $\mathrm{M}$. The subtalar joint and symptoms of turning over on the ankle. A new method of evaluation using tomography. Am J Ortho. 1962;4:16-19.

10. Hertel J, Denegar CR, Monroe MM, Stokes WL. Talocrural and subtalar joint instability after lateral ankle sprain. Med Sci Sports Exerc. 1999;31(11):1501-1508.

11. Meyer JM, Garcia J, Hoffmeyer P, Fritschy D. The subtalar sprain. A roentgenographic study. Clin Orthop Relat Res. 1986;226: 169-173.

12. Freeman, MAR. Instability of the foot after injuries to the lateral ligament of the ankle. J Bone Joint Surg Br. 1965b;47:669-677.

13. Tropp HP, Odenrick, Gillquist J. Stabilometry recordings in functional and mechanical instability of the ankle joint. Int J Sports Med. 1985;6: $180-182$.

14. Hubbard TJ, Kovaleski JE, Kaminski TW. Reliability of intratester and intertester measurements derived from an instrumented ankle arthrometer. J Sport Rehabil. 2003;12:208-220.
15. Kovaleski JE, Hollis JM, Heitman RJ, Gurchiek LR, Pearsall AW. Assessment of ankle-subtalar-joint-complex laxity using an instrumented ankle arthrometer: An experimental cadaveric investigation. $J$ Athl Train. 2002;37:467-474.

16. Martin DE, Kaplan PA, Kahler DM, Dussault R, Randolph BJ. Retrospective evaluation of graded stress examination of the ankle. Clin Orthop Relat Res. 1996;328:165-170.

17. Mattacola CG, Dwyer MK. Rehabilitation of the ankle after acute sprain or chronic instability. J Athl Train. 2002;37(4):413-429.

18. Freeman MAR. Treatment of ruptures of the lateral ligament of the ankle. J Bone Jt Surg. 1965;47B:661-668.

19. Avci S, and Sayli U. Comparison of the results of short-term rigid and semi-rigid cast immobilization for the treatment of grade 3 inversion injuries of the ankle. Injury. 1998;29:581-584.

20. Cetti R, Christensen SE, Corfitzen MT. Ruptured fibular ankle ligament: plaster or Pliton brace? Br J Sports Med. 1984;18:104-109.

21. Konradsen L, Holmer P, Sondergaard L. Early mobilizing treatment for grade III ankle ligament injuries. Foot and Ankle. 1991;12: 69-73.

22. Munk B, Holm-Christensen K, Lind T. Long-term outcome after ruptured lateral ankle ligaments. A prospective study of three different treatments in 79 patients with 11-year follow-up. Acta Orthop Scand. 1995;66:452-454.

23. Broström L. Sprained ankles V. Treatment and prognosis in recent ligament ruptures. Acta Chir Scand. 1966;132:537-550.

24. Eiff MP, Smith AT, Smtih GE. Early mobilization versus immobilization in the treatment of lateral ankle sprains. Am J Sports Med. 1994; 22:83-88.

25. Beynnon BD, Murphy DF, Alosa DM. Predictive factors for lateral ankle sprains: A literature review. J Athl Train. 2002;37:376-380.

26. Ekstrand J, Gillquist J. Soccer injuries and their mechanisms: a prospective study. Med Sci Sports Exerc. 1983;15:267-270.

27. Ekstrand J, Tropp H. The incidence of ankle sprains in soccer. Foot Ankle. 1990;11:41-44.

28. Baumhauer JF, Alosa DM, Renström PA, Trevino S, Beynnon B. A prospective study of ankle injury risk factors. Am J Sports Med. 1995; 23:564-570.

29. Sitler MR, Ryan J, Wheeler B, et al. The efficacy of a semirigid ankle stabilizer to reduce acute ankle injuries in basketball: a randomized clinical study at west point. Am J Sports Med. 1994;22:454-461.

30. Dahle LK, Mueller MJ, Delitto A, Diamond JE. Visual assessment of foot type and relationship of foot type to lower extremity injury. J Orthop Sports Phys Ther. 1991;14:70-74.

31. Tropp H, Ekstrand J, Gillquist J. Stabilometry in functional instability of the ankle and its value in predicting injury. Med Sci Sports Exerc. 1984;16:64-66.

32. Olmsted LC, Vela LI, Denegar CR, Hertel J. Prophylactic ankle taping and bracing: A numbers-needed-to-treat and cost-benefit analysis. J Athl Train. 2004;39:95-100.

33. Bernier J, Perrin DH. Effect of coordination training on proprioception of the functionally unstable ankle. J Orthop Sports Phys Ther. 1998; 27(4):264-275.

34. Mattacola CG, Lloyd JW. Effects of a 6-week strength and proprioception training program on measures of dynamic balance: a single-case design. J Athl Train. 1997;32:127-135.

35. Hubbard TJ, Cordova ML. Mechanical Instability after an Acute Lateral Ankle Sprain. Arch Phys Med Rehabil. 2009;90:1142-1146.

36. Lamb SE, Marsh JL, Hutton JL, Nakash R, Cooke MW; Collaborative Ankle Support Trial (CAST Group). Mechanical supports for acute, severe ankle sprain: a pragmatic, multicentre, randomised controlled trial. Lancet. 2009;373:575-581.

37. Beynnon BD, Renström PA, Haugh L, Uh BS, Barker H. A prospective, randomized clinical investigation of the treatment of first-time ankle sprains. Am J Sports Med. 2006;34:1401-1412.

38. Maitland GD. Peripheral manipulation. 2nd ed. Sydney, AUS: Butterworths; 1984. 
39. Maitland GD. Passive movement techniques of intra-articular and peri-articular disorders. Aust J Physiother. 1985;31(1):3-8.

40. Mulligan BR. Extremity joint mobilization combined with movements. N Z J Physiother. 1992;20:28-29.

41. Mulligan BR. Mobilization with movement (MWM's). J Man Manip Ther. 1993;1:154-156.

42. Mulligan BR. Manual Therapy: "Nags", "Snags", "MWMS" etc. 5th ed. Wellington, NZ: APN Print Limited; 2004.

43. Bleakley CM, McDonough M, MacAuley DC. Some conservative strategies are effective when added to controlled mobilization with external support after acute ankle sprain: a systematic review. Aust $J$ Physiother. 2008;54:7-20.

44. Brantingham JW, Globe G, Pollard H, Hicks M, Korporaal C, Hoskins W. Manipulative therapy for lower extremity conditions: expansion of literature review. J Manipulative Physiol Ther. 2009;32:53-71.

45. van der Wees PJ, Lenssen AF, Hendriks EJM, Stomp DJ, Dekker J, de Bie RA. Effectiveness of exercise therapy and manual mobilization in acute ankle sprain and function instability: a systematic review. Aust $J$ Physiother. 2006;52:27-37.

46. Vicenzino B, Paungmali A, Teys P. Mulligan's mobilizationwith-movement, positional faults and pain relief: current concepts from a critical review of literature. Man Ther. 2007;12:98-108.

47. Maitland GD. Peripheral Manipulation. 2nd ed. Sydney, AUS: Butterworths; 1984.

48. Whitman JM, Childs JD, Walker V. The use of manipulation in a patient with an ankle sprain injury not responding to conventional management: a case report. Man Ther. 2005;10:224-231.

49. O'Brien T, Vicenzino B. A study of the effects of Mulligan's mobilization with movement treatment of lateral ankle pain using a case study design. Man Ther. 1998;3:78-84.

50. Dananberg HJ. Manipulation of the ankle as a method of treatment for ankle and foot pain. J Am Podiatr Med Assoc. 2004;94(4): 395-399.

51. Wikstrom EA, McKeon PO. Manipulative therapy effectiveness following acute lateral ankle sprains: a systematic review. Athletic Training and Sports Health Care. 2010; In Press.

52. Pellow JE, Brantingham JW. The efficacy of adjusting the ankle in the treatment of subacute and chronic grade I and grade II ankle inversion sprains. J Manipulative Physiol Ther. 2001;24(1):17-24.

53. Eisenhart AW, Gaeta TJ, Yens DP. Osteopathic manipulative treatment in the emergency department for patients with acute ankle injuries. J Am Osteopath Assoc. 2003;103(9):417-421.

54. Coetzer D, Brantingham JW, Nook B. The relative effectiveness of piroxicam compared to manipulation in the treatment of acute grades 1 and 2 inversion ankle sprains. J Neruomusculoskelet Syst. 2001;9: $1-12$.

55. Whitman JM, Cleland JA, Mintken P, et al. Predicting short-term response to thrust and nonthrust manipulation and exercise in patients post inversion ankle sprain. J Orthop Sports Phys Ther. 2009; 39(3): 188-200.

56. Green T, Refshauge K, Crosbie J, Adams R. A randomized controlled trial of a passive accessory joint mobilization on acute ankle inversion sprains. Phys Ther. 2001;81:984-994.

57. Andersen S, Fryer G, McLaughlin P. The effect of talocrural joint manipulation on range of motion at the ankle joints in subjects with a history of ankle injury. Australas Chiropr Osteopathy. 2003;11: $57-62$.

58. Fryer G, Mudge J, McLaughlin P. The effect of talocrural joint manipulation on range of motion at the ankle. J Manipulative Physiol Ther. 2002;25:384-390.

59. Nield S, Davis K, Latimer J, Maher C, Adams R. The effect of manipulation on range of movement at the ankle joint. Scand J Rehabil Med. 1993;25:161-166.

60. de Souza MvS, Venturini C, Teixeria LM, Chagas MH, de Resende MA Force-displacement relationship during anterioposterior mobilization of the ankle joint. J Manipulative Physiol Ther. 2008;31:285-292.
61. Venturini C, Penedo MM, Peixoto GH, Chagas MH, Ferreira ML, de Resende MA. Study of the force applied during anteroposterior articular mobilization of the talus and its effect on the dorsiflexion range of motion. J Manipulative Physiol Ther. 2007;30:593-597.

62. Landrum EL, Kellen BM, Parente WR, Ingersoll CD, Hertel J. Immediate effects of anterior-to-posterior talocrural joint mobilization after prolonged ankle immobilization. J Man Manip Ther. 2009; 16(2):100-105.

63. Lopez-Rodriguez S, Fernandez de-las-Penas C, Alburquerque-Sendin F, Rodriguez-Blanco C, Palomeque-del-Cerro L. Immediate effects of manipulation of the talocrural joint on stabilometry and baropodometry in patients with ankle sprain. J Manipulative Physiol Ther. 2007;30: 186-192.

64. Evans T, Hertel J, Sebastianelli W. Bilateral deficits in postural control following lateral ankle sprain. Foot Ankle Int. 2004;25(11) 833-839.

65. McKeon PO, Hertel J. Systematic review of postural control and lateral ankle instability, part 1: can deficits be detected with instrumented testing? J Athl Train. 2008;43(3):293-304.

66. Wikstrom EA, Naik S, Lodha N, Cauraugh JH. Balance capabilities after lateral ankle trauma and intervention: a meta-analysis. Med Sci Sports Exerc. 2009;41:1287-1295.

67. Bullock-Saxton JE. Local sensation changes and altered hip muscle function following severe ankle sprain. Phys Ther. 1994;74(1): $17-28$.

68. Bullock-Saxton JE, Janda V, Bullock MI. The influence of ankle sprain injury on muscle activation during hip extension. Int $J$ Sports Med. 1994;15(6):330-334.

69. Tropp H, Ekstrand J, Gillquist J. Stabilometry in functional instability of the ankle and its value in predicting injury. Med Sci Sports Exer. 1984;16(1):64-66.

70. Wang HK, Chen CH, Shiang TY, Jan MH, Lin KH. Risk-factor analysis of high school basketball-player ankle injuries: a prospective controlled cohort study evaluating postural sway, ankle strength, and flexibility. Arch Phys Med Rehabil. 2006;87(6):821-825.

71. Emery C, Rose M, McAllister J, Meeuwisse W. A prevention strategy to reduce the incidence of injury in high school basketball: a cluster randomized controlled trial. Clin J Sport Med. 2007;17(1):17-24.

72. Holme E, Magnusson SP, Becher K, Bieler T, Aargaar P, Kjar M. The effect of supervised rehabilitation on strength, postural sway, position sense and reinjury risk after acute ankle ligament sprain. Scand J Med Sci Sports. 1999;9(2):104-109.

73. McGuine TA, Keene JS. The effect of a balance training program on the risk of ankle sprains in high school athletes. Am J Sports Med. 2006;34(7):1103-1111.

74. McHugh M, Tyler T, Mirabella M, Mullany M, Nicholas S. The effectiveness of a balance training intervention in reducing the incidence of noncontact ankle sprains in high school football players. Am J Sports Med. 2007;35(8):1289-1294.

75. Beck S, Taube W, Gruber M, Amtage F, Gollhofer A, Schubert M. Task-specific changes in motor evoked potentials of lower limb muscles after different training interventions. Brain Res. 2007;1179: 51-60.

76. Gruber M, Taube W, Gollhofer A, Beck S, Amtage F, Schubert M. Training-specific adaptations of $\mathrm{H}$ - and stretch reflexes in human soleus muscle. J Mot Behav. 2007;39:68-78.

77. Taube W, Gruber M, Beck S, Faist M, Gollhofer A, Schubert M. Cortical and spinal adaptations induced by balance training: correlation between stance stability and corticospinal activation. Acta Physiol (Oxf). 2007;189:347-358

78. Taube W, Kullmann N, Leukel C, Kurz O, Amtage F, Gollhofer A Differential reflex adaptations following sensorimotor and strength training in young elite athletes. Int J Sports Med. 2007;28:999-1005.

79. Horak FB, Henry SM, Shumway-Cook A. Postural perturbations: new insights for treatment of balance disorders. Phys Ther. 1997;77(5): $517-533$. 
80. Bahr R, Lian O, Bahr IA. A twofold reduction in the incidence of acute ankle sprains in volleyball after the introduction of an injury prevention program: a prospective cohort study. Scand J Med Sci Sports. 1997; 7(3):172-177.

81. Collins JJ, Priplata A, Gravielle D, Niemi J, Harry J, Lipsitz LA. Noise-enhanced human sensorimotor function. IEEE Eng Med Biol Mag. 2003;22:76-83.

82. Gravielle D, Laughton C, Dhruv N, et al. Noise-enhance balance control in older adults. Neuroreport. 2002;13:1853-1856.

83. Priplata A, Niemi J, Harry J, Lipsitz LA, Collins JJ. Vibrating insoles and balance control in elderly people. Lancet. 2003;362:1123-1124.

84. Priplata A, Niemi J, Salen M, Harry J, Lipsitz LA, Collins JJ. Noise-enhanced human balance control. Phys Rev Lett. 2002;89: 238101.

85. Ross SE, Guskiewicz KM. Examination of static and dynamic postural stability in individuals with functionally stable and unstable ankles. Clin J Sport Med. 2004;14(6):332-338.

86. Ross SE, Guskiewicz KM. Effect of coordination training with and without stochastic resonance stimulation on dynamic postural stability of subjects with functional ankle instability and subjects with stable ankles. Clin J Sport Med. 2006;16:323-328.
87. McNevin NH, Wulf G. Attentional focus on supra-postural tasks affects postural control. Hum Mov Sci. 2002;21:187-202.

88. Wulf G, McNevin NH, Shea CH. The automaticity of complex motor skill learning as a function of attentional focus. $Q J$ Exp Psychol A. 2001;54:1143-1154.

89. Vuillerme N, Nafiti G. How attentional focus on body sway affects postural control during quiet standing. Psychol Res. 2007;71(2): 192-200.

90. Laufer Y, Rotem-Lehrer N, Ronen Z, Khayutin G, Rozenberg I. Effect of attention focus on acquisition and retention of postural control following ankle sprain. Arch Phys Med Rehabil. 2007;88(1):105-108.

91. Rotem-Lehrer N, Laufer Y. Effect of focus of attention on transfer of a postural control task following an ankle sprain. J Orthop Sports Phys Ther. 2007;37(9):564-569.
Open Access Journal of Sports Medicine

\section{Publish your work in this journal}

Open Access Journal of Sports Medicine is an international, peer-reviewed, open access journal publishing original research, reports, reviews and commentaries on all areas of sports medicine. The manuscript management system is completely online and includes a very quick and fair peer-review system.

\section{Dovepress}

Visit http://www.dovepress.com/testimonials.php to read real quotes from published authors. 